\title{
Original Article \\ Osteosynthesis of Unstable Fractures of Distal Radius with Volar Locking Plate
}

\author{
PRADHAN RL. SHARMA S, PANDEY BK, MANANDHAR RR, LAKHEY S, RIJAL KP \\ Department of Orthopaedic Surgery, Kathmandu Medical College Teaching Hospital, Sinamangal, Kathmandu, Nepal
}

\begin{abstract}
BACKGROUND: Various surgical treatment methods are available for unstable distal radius fractures. Clinical and radiological outcome with volar locking plate has been very satisfactory. The purpose of this prospective study is to evaluate the results of the treatment of unstable fractures with the volar locking plate with regard to loss of reduction, functional outcome and complications.
\end{abstract}

METHODS: Unstable distal radius fractures were enrolled for the study from May 2008 until July 2010. All patients were treated with $3.5 \mathrm{~mm}$ distal radius volar locking plate and assessed by clinical and radiological examination. The clinical scoring chart modified by Cooney was used to evaluate the functional outcome.

RESULTS: Eighteen male and 12 female patients with the average age of 42.53 (range 30-64years) were followed up for a period of 9 to 34 months (average. 23 months). There were fourteen A3 fractures, nine $\mathrm{C} 1$ fractures, six C2 fractures, and one C3 fracture, whereas one had a Gustilo grade I open wound on the volar aspect. Seven of the fractures had associate fracture of the ulnar styloid. The functional outcome was excellent in $23(76 \%)$, good in $6(20 \%)$, fair in $1(4 \%)$ and none had poor outcome. There were very few complications in our series.

CONCLUSION: Unstable fractures of distal radius treated by open reduction with volar locking plate provides adequate fixation with no collapse in reduction and also have satisfactory functional outcome with minimal complications.

KEY WORDS: distal radius fractures, volar locking plate, functional outcome, complications

\section{INTRODUCTION}

Unstable fractures of the distal radius are generally treated with operative treatment to restore the congruence and kinematics of the wrist joint. Several surgical modalities are available, such as percutaneous pinning, external fixation, and open reduction/internal fixation with volar/ dorsal plating. Tscherne showed that between $20 \%$ and $30 \%$ heal with an unsatisfactory anatomical and functional result, and others have reported a high incidence of malunion, radial shortening, and articular incongruity with a poor functional outcome. ${ }^{1}$ Anatomical articular reduction greatly reduces the incidence of post-traumatic osteoarthrosis and that the quality of reduction relates directly to the final outcome. ${ }^{2}$ Although good to excellent results have been shown with plate and external fixation for these unstable fractures, the need for prolonged immobilization is a concern. ${ }^{3,4,5}$ The advantages of plate osteosynthesis are direct fracture reduction, stable rigid fixation, and the possibility of immediate postoperative motion. ${ }^{6,7}$ Open reduction of the fracture allows reduction of the fracture under direct vision and leads to accurate restoration of anatomy. ${ }^{8,9}$ In the early postoperative period, patients who had been managed with open reduction and internal fixation had better range of motion and strength and lower DASH scores than did those who had been managed with closed reduction and percutaneous pin fixation. ${ }^{10}$ Dorsal plates are associated with tendon rupture, tenosynovits, reoperation, and $25 \%$ of collapse while the complication of volar plating is relatively low. ${ }^{11}$ The volar surface of the distal radius may be biologically more acceptable for open reduction and internal fixation 
than the dorsal surface because the flexor tendons are not as close to the bone surface as the extensor tendons. ${ }^{12}$ Recent studies have shown that volar locking plate system are biomechanically more stable than nonlocking plates and even maintain the anatomy of dorsally displaced intraand extra-articular distal radius fractures. ${ }^{13,14}$ Compared with dorsal and radial plates, volar plates are associated with fewer soft tissue complications and have become increasingly popular over recent years to treat dorsally displaced distal radial fractures since the introduction of angle stable locking plates. ${ }^{15,16}$ In addition to maintaining fracture position, angle stable locking plates also provide sufficient fracture stability to enable patients to mobilize injured joints rapidly in the postoperative period. ${ }^{17}$ The objective of this study is to investigate the functional outcome of management of unstable distal radius fractures with volar locking plates in our setup.

\section{MATERIALS AND METHODS}

All patients with unstable distal radial fractures treated with locked volar plating at Kathmandu Medical College Teaching Hospital from May 2008 until July 2010 were included. The method of treatment was chosen based on surgeon's preference.

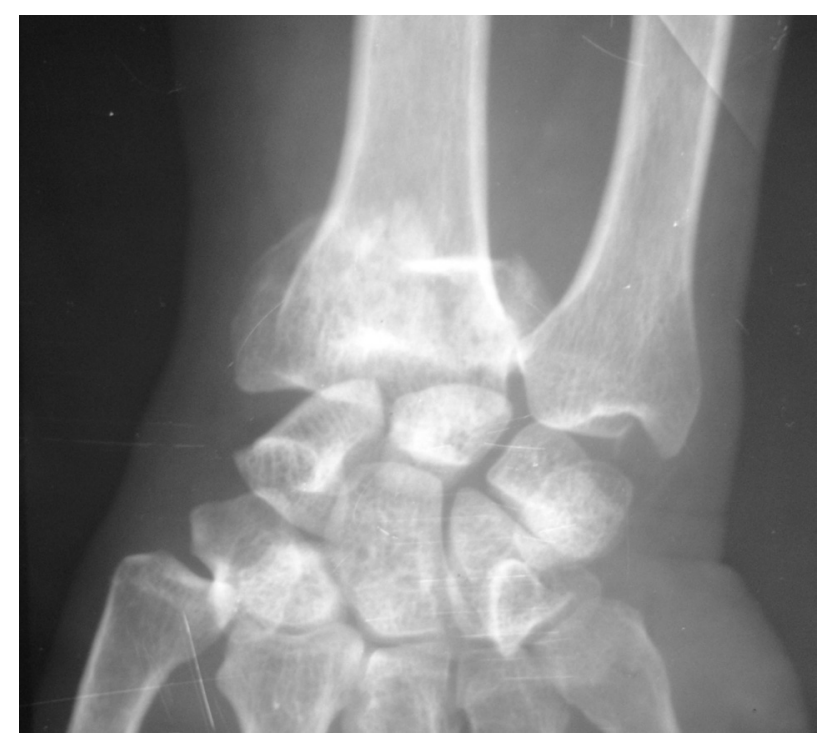

Fig. 1A Unstable distal radius fracture (AP view)
All patients were operated by the first author (RLP) or under his supervision. There were 30 cases whose initial data were recorded prospectively. Patients treated with closed reduction and cast application, external fixation alone or with percutaneous $\mathrm{K}$ wire fixation and dorsal plating were excluded from the study. All patients had unstable intra- and extra-articular distal radius fractures with volar and dorsal metaphyseal comminution and were classified according to the AO/OTA classification. (Figure 1) We operated on all unstable distal radius fractures who did not meet the criteria as suggested in (Table 1). ${ }^{18}$

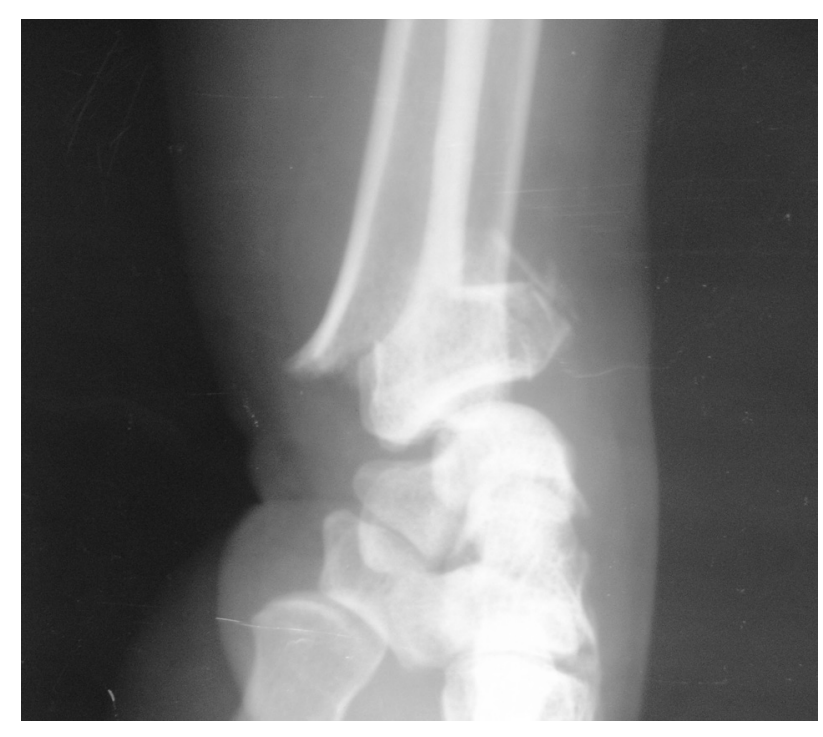

Fig. 1B Unstable distal radius fracture (Lateral view)

Table 1

Guidelines for Acceptable Reduction of Distal Radius Fractures $^{18}$

1. Radial shortening $<5 \mathrm{~mm}$ at the DRUJ compared with the contralateral side

2. Radial inclination on posteroanterior radiographs $>15^{\circ}$

3. Sagittal tilt on the lateral projection between $15^{\circ}$ dorsal tilt and $20^{\circ}$ volar tilt

4. Intra-articular step-off or gap $<2 \mathrm{~mm}$ of the radiocarpal joint 10

5. Articular incongruity $<2 \mathrm{~mm}$ of the sigmoid notch of the distal radius 


\section{Surgical Technique}

Surgery was performed under axillary block anesthesia in all but 8 patients in whom general anesthesia was necessary and all patients surgery were done under tourniquet control. The distal radius was exposed by a volar approach between the flexor carpi radialis tendon as described by Chung and Petruska. ${ }^{19}$ An 8 -cm incision is made on the radial border of the flexor carpi radialis tendon. The $\mathrm{v}$-shape of the distal part of the incision provides better access to the articular surface. The incision is carried through the flexor carpi radialis tendon sheath. The tendon sheath is opened and the forearm fascia on the radial border of the flexor carpi radialis is incised. The forearm fascial incision was made along the radial side of the flexor carpi radialis tendon to ensure that the palmar cutaneous branch of the median nerve, which arises near the ulnar side of the flexor carpi radialis tendon was protected. The index finger of the surgeon is then swept under the flexor pollicis longus muscle to gain rapid exposure of the pronator quadratus. An L-shaped incision is made over the radial border of the pronator quadratus to prevent full elevation of that structure from the radius. For ease of fracture reduction, an osteotome is inserted into the fracture, over the dorsal cortex, to completely disimpact the distal fracture fragment. Fracture reduction is facilitated through ligamentotaxis by applying traction to the fingers. The assistant distracts the fracture while the surgeon reduces it through manual manipulation. For dorsal comminuted fractures, the surgeon can use manual pressure to mold the dorsal fragments into anatomical reduction. A volar plate $(3.5 \mathrm{~mm})$ is placed by first drilling the central oval hole. After placement of the central screw in the oval slot, a C-arm is used to ensure that the plate is positioned optimally. The oval hole provides the option of moving the plate distally or proximally, depending on the fracture pattern. Next, a screw is placed in the central distal hole, and then the remaining screws are placed.
When the distal fracture fragment is being reduced into anatomic position, it is important for an assistant to apply traction continuously to the fingers of the operatively treated hand. In many patients, the pronator quadratus is quite shredded by the fracture and complete coverage of the plate is not possible wherein it was sutured to the edge of the brachioradialis to provide coverage for the distal plate. This prevents irritation of the flexor tendons by the plate. The carpal tunnel was not decompressed in any of the patients.

\section{Postoperative Protocol}

Patients with a stable radioulnar joint after fixation of the distal part of the radius were placed in a volar splint for two weeks till suture removal which was done on the fourteenth post operative day. After this time, under the guidance of a physiotherapist, the patient also starts active range-of-motion exercises and continued with that exercise regimen for the next six weeks. For the next four weeks patients use a removable wrist splint. Six weeks after surgery, the splint was removed and a strengthening exercise program was begun. Unrestricted activities are allowed twelve weeks after surgery.

\section{Patient Assessment}

Patients were followed up at 6 weeks, 3 months, 6 months and one year after surgery and radiographs taken. Functional evaluation was assessed with the clinical rating as devised by Cooney ${ }^{20}$ (modified from Green an O'Brien) (Table 2) was given to each patient as follows: pain, functional status, range of motion, and grip strength measured as percentage of normal (range, 0-25 points) Points were accumulated for the four categories and a final rating were obtained as follows: excellent, 90-100 points, good, 80-90 points; fair, $65-80$ points, and poor, less than 65 points. 
Table 2 .

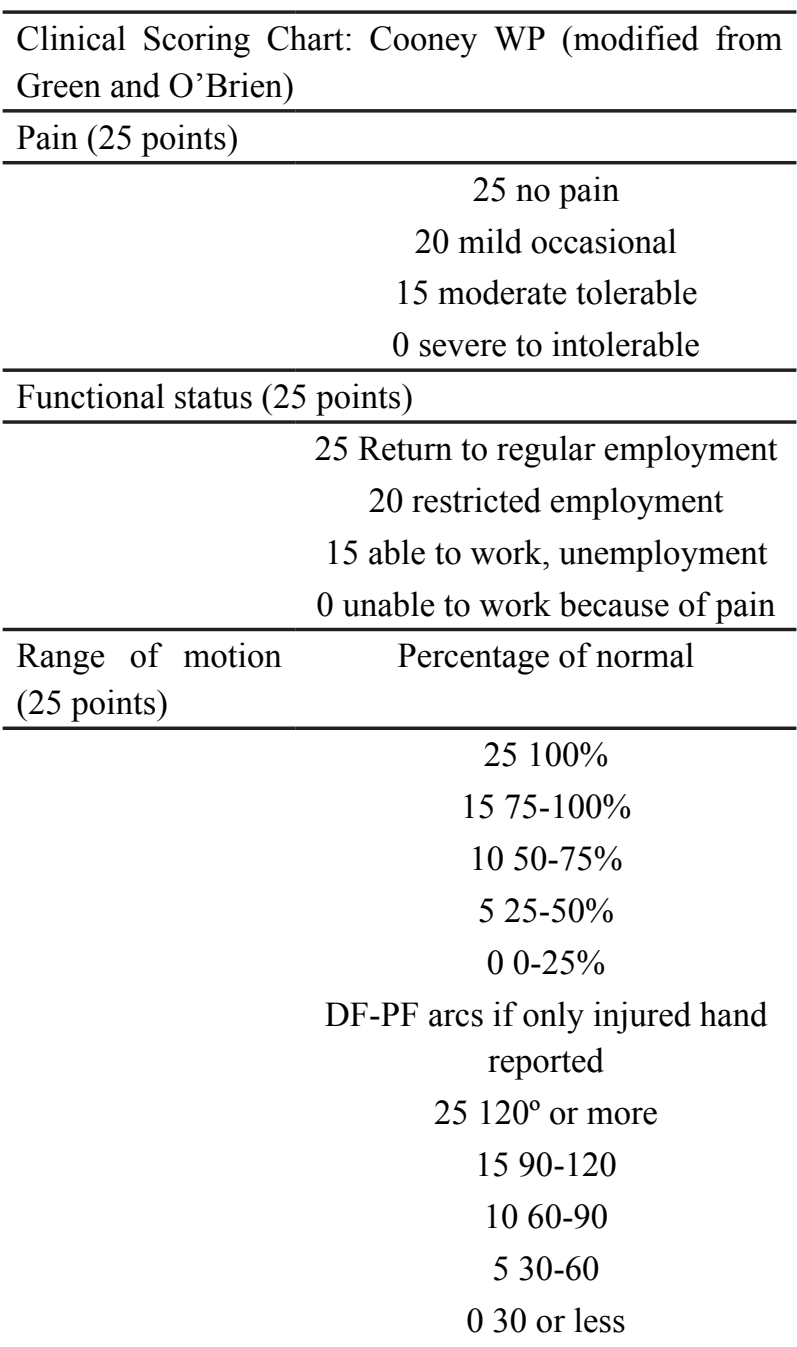

\begin{tabular}{lc}
\hline $\begin{array}{l}\text { Grip Strength (25 } \\
\text { points) }\end{array}$ & Percentage if normal \\
\hline & $25100 \%$ \\
$1575-100 \%$ \\
$1050-75 \%$ \\
$525-50 \%$ \\
$00-25 \%$ \\
\hline
\end{tabular}

\section{RESULTS}

There were 30 patients treated with volar locking plate system in this study. Eighteen male and 12 female patients with the average age of 42.53 (range 30-64) were followed up for a period of 9 to 34 months (av.23 months). All fractures were classified according to the AO/OTA classification. There were 14 A3 fractures, $9 \mathrm{C} 1$ fractures, $6 \mathrm{C} 2$ fractures, and one $\mathrm{C} 3$ fractures. Only one had a Gustilo grade I open wound on the volar aspect. Seven of the fractures had associate fracture of the ulnar styloid but none underwent any operative treatment as it has been shown that the functional outcome was good even though the ulnar styloid was not operated ${ }^{21}$. In all but two fractures the index procedure was volar locking plate. Two patients were previously treated with external fixation alone wherein the fracture collapsed after three weeks of fixation. The mean time to union was 8 weeks (range 6-12 weeks). At the time of final followup (minimum 9 months) the clinical scoring chart was done according to Green and O'Brien as modified by Cooney. The results were: excellent in $23(76 \%)$, good in $6(20 \%)$, fair in $1(4 \%)$ and none had poor outcome. (Figures 4, 5) There was one patient (who had previous treatment with external fixator) with screw penetration in the joint wherein the fracture collapsed even though bone substitutes were used. The plate was removed after four months. This patient had a fair outcome. There were two cases of superficial wound infection that settled well with oral antibiotics. No patients had complex regional pain syndrome or non union and none had extensor tendon irritation or ruptures.

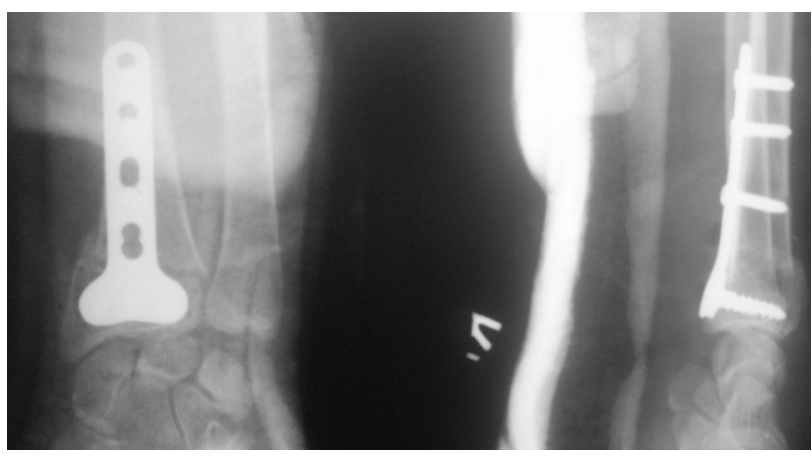

Fig. 3 Post-operative radiograph treated with $3.5 \mathrm{~mm}$ volar locking plate.

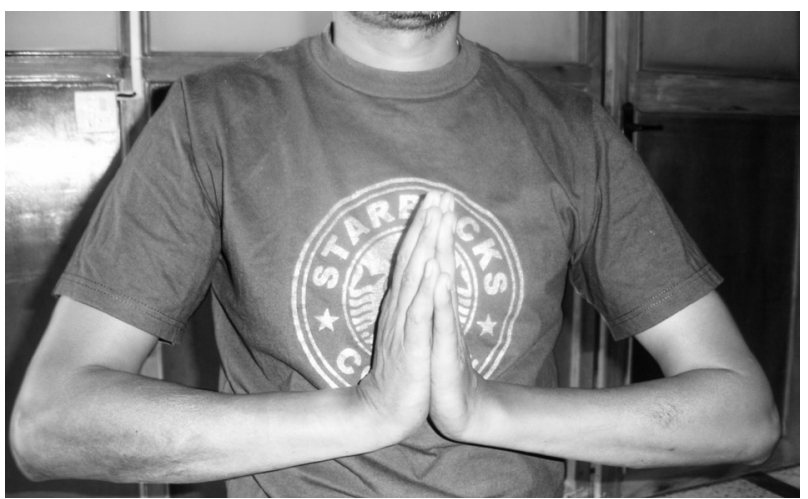

Fig. 3A Clinical pictures of patients after 24 months follow-up with excellent results 


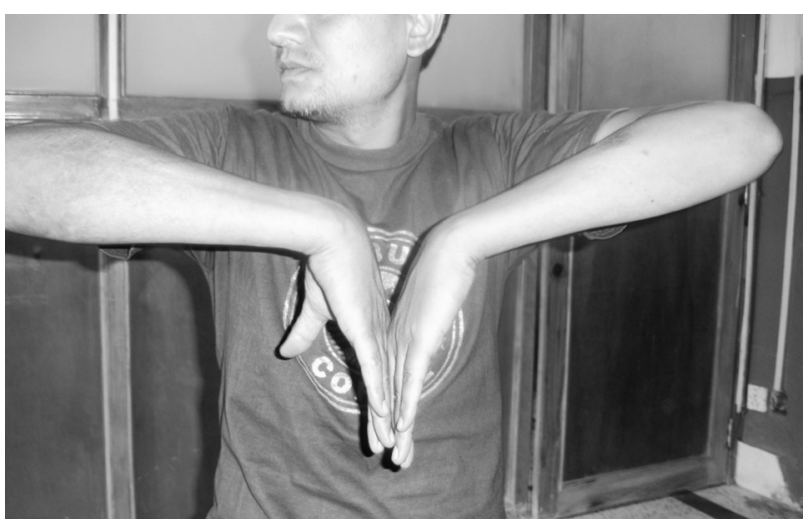

Fig. 3B Clinical pictures of patients after 24 months follow-up with excellent results

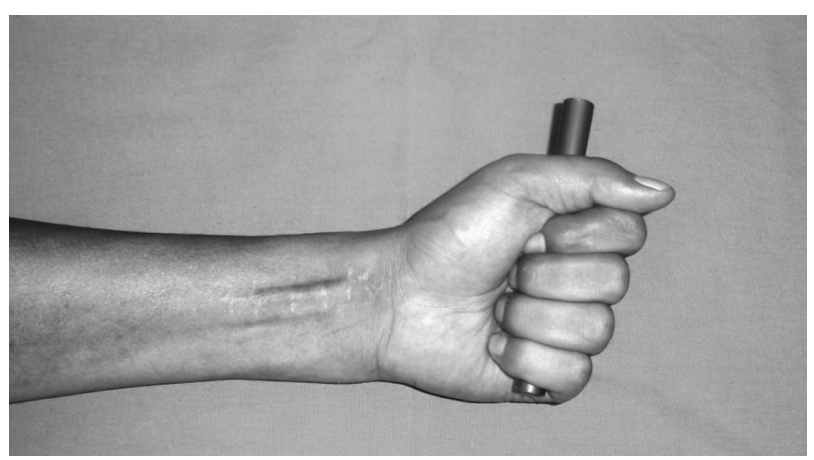

Fig. 3C Clinical pictures of patients after 24 months follow-up with excellent results

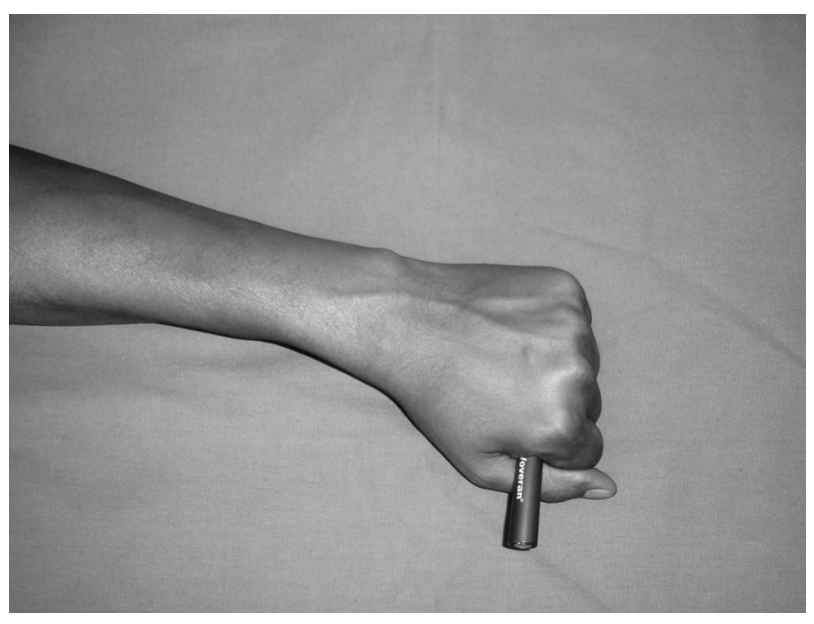

Fig. 3D Clinical pictures of patients after 24 months follow-up with excellent results

\section{DISCUSSION}

In surgical treatment of unstable distal radial fractures, the main aim is to achieve and maintain anatomic reduction and minimize the poor long term failure associated with unsatisfactory treatment. The biomechanical results show that locking volar plates provides significantly greater resistance to fracture gap motion compared with standard volar plates in a dorsally comminuted distal radius fractures. ${ }^{22}$ Biomechanical studies comparing volar fixedangle fixation plates with conventional dorsal implants report volar fixed-angle fixation plates are stronger. ${ }^{13}$ Fixed-angle volar plates prove stronger under cyclical loading tests than dorsal implants as the implant- bone interface is the limiting factor. ${ }^{13}$ In a locking screw system, the threaded screw head locks in the threaded screw hole of the plate to attain stability. Consequently, axial forces in the bone are transmitted to the plate rather than the screw, and no screw toggle can occur. Because stability with a locking screw does not require compression between the bone and the plate, the periosteal blood supply under the plate is preserved. ${ }^{18}$

Although there are few complications associated with volar locking plate system but are less as compared to dorsal plating even for dorsal communited fractures. In the study by Ruch and Papadonikolakis, ${ }^{11}$ the volar collapse occurred regardless of the type of dorsal plate used and that volar plating was associated with fewer complications than dorsal plating. In the dorsal plating group there was a statistically significant association of volar collapse of the distal fragment when the distal screws were pointing proximally.

Volar plating for dorsally displaced, unstable fractures of the distal radius has several advantages compared with dorsal plating. The volar approach, fracture reduction, and volar plating techniques are easier than dorsal plating. Volar plating preserves vascular supply to dorsal metaphyseal fragments and does not cause extensor tendon problems. $^{7}$ When the quality of the pronator quadratus muscle is good, volarly placed plates are almost covered with the pronator quadratus except the distal edge of the plate. ${ }^{19}$

Arora et al. ${ }^{23}$ did not use bone graft or artificial bone because the good mechanical stiffness of the $3.5-\mathrm{mm}$ locking compression plate, provided angular stability by screws locked to the plate This was efficient in restoring normal axial force distribution and has been proved in a biomechanical study. ${ }^{24}$ 
Similar to Hakimi et al. ${ }^{25}$ series we did not have any problems related with extensor tendons. It may be because we used shorter length distal screws and constantly checked in fluoroscopy in different positions for the placement and the length of the screws. We positioned the plates as well as the screws of the distal row under radiological control in lateral view. Recently, rotational fluoroscopy has been advocated to avoid penetration of the joint by distal screws during volar locking plating. ${ }^{26}$

Most complications of distal radial fracture treatment are the result of prolonged immobilization of the wrist and regardless of the method used to treat distal radial fractures, the most important factors that effect long-term function are early mobilization and restoration of normal anatomy. ${ }^{27}$ Many surgeons have different opinions regarding the degree of malunion, that is, clinically acceptable, we consider the following to be compatible with reasonable long-term function: radial shortening of less than $5 \mathrm{~mm}$, radial inclination of greater than 15 degree angle, volar tilt of between 15-degree angle of dorsal tilt and 20- degree angle of volar tilt, intra-articular incongruity of the radiocarpal joint of less than $2 \mathrm{~mm}$, and, intra-articular incongruity of the distal radioulnar joint of less than $5 \mathrm{~mm} .{ }^{28}$

In addition to restoring anatomy, the other real advantage of using volar locking plates compared with other treatment methods is improved fracture stability that permits unprotected early mobilization of the injured wrist. Osada et $\mathrm{al}^{7}$ beleive that postoperative splinting of the wrist has little effect on preventing redisplacement of the fracture fragment as long as active digit movement exercise is started immediately after the operation. Physiologically, active wrist joint motion during daily activities have been estimated to cause $100 \mathrm{~N}$ axial load across the wrist joint, whereas active digit flexion has been estimated to produce $250 \mathrm{~N}$ axial load across the wrist joint. They stated that because this plate was sufficiently strong there were no fractures that needed postoperative immobilization in their series. This plate enabled them to start active range of motion exercises of the wrist and the forearm in the immediate postoperative period. We, however, applied a volar slab for two weeks till suture removal and then stated active wrist motion exercises and similar protocol has been practiced in many studies. ${ }^{10,26}$

Rozental et al. ${ }^{10}$ found that, in the early postoperative period, patients who had been managed with open reduction and internal fixation had better range of motion and strength and lower DASH scores than did those who had been managed with closed reduction and percutaneous pin fixation. This difference was particularly pronounced in the first six and nine weeks after the injury and then decreased over time. We also believe that the early rehabilitation after volar locking plate is seen in the first six weeks after surgery and renders patients to be more confident in using their wrist.

Knight, et al. ${ }^{29}$ found two mechanisms of collapse: angular and axial shortening. They found that placing the distal screws close to the subchondral bone of the distal fragment caused fracture collapse and screw penetration were more likely to occur when the screws were close to the subchondral bone and believed that the risk of collapse is related to the severity of the metaphyseal comminution. In fractures with a large metaphyseal defect, often the only possible placement of the distal screws is in the subchondral bone whereas in those with a smaller metaphyseal defect and therefore a larger distal fragment, placement of the screws is possible further from the subchondral bone. With a large unfilled metaphyseal defect, subsidence of the distal fragment would occur to some extent around the screws, and if the collapse was sufficiently severe, penetration of the screws into the radiocarpal joint would result. We try to place the distal screw in the subchondral bone and have not had any problems except in one case where the surgery was revised after failure with external fixation. However, we try not to use locking plate if the distal fragment is too small and the space is not enough to hold the screw, as we use a $3.5 \mathrm{~mm}$ system. If we use the newly available $2.4 \mathrm{~mm}$ locking plate system we may be able to overcome this problem. We also agree with Knight et al, and now augment large metaphyseal defects with bone graft substitutes in cases with severe metaphyseal comminution and believe that this may prevented collapse and screw penetration into the joint.

In seven our patients there was associated ulnar styloid fractures which were not fixed with any internal fixation. It had been clearly mentioned that the presence of ulnar styloid fracture does not adversely affect the outcome in patients with a fracture of the distal radius treated by volar locking plating. ${ }^{21}$

Limitations of our study include its lack of controls and relatively small number of cases. 


\section{CONCLUSION}

We have shown that $3.5 \mathrm{~mm}$ fixed-angle volar locking plating of unstable fractures of the distal radius can achieve excellent to good functional outcome in many patients, with limited complications. Careful assessment of screw length and placement of the plate is necessary to reduce collapse and tendon irritation or rupture. Not all unstable fractures with intra-articular comminution or very small distal fragments are suitable for volar locking plates and other methods of treatment should be applied in dealing with such fractures.

\section{REFERENCES:}

1. Tscherne H, Jahne J. Aktueller Stand der Therapie der distalen Radiusfraktur (Current status of the treatment of distal radius fracture). Unfallchirurg. 1990 93:157-164

2. Knirk JL, Jupiter JB. Intra-articular fractures of the distal end of the radius in young adults. J Bone Joint Surg Am.1986; 68:647-59.

3. Nakata RY, Chand Y, Matiko JD, Frykman GK, Wood VE. External fixators for wrist fractures: a biomechanical and clinical study. J Hand Surg Am.1985;10: 845-51.

4. Jenkins NH, Jones DG, Johnson SR, Mintowt-Czyz WJ. External fixation of Colles' fractures. An anatomical study. J Bone Joint Surg. 1987;69: Br 207-11.

5. Pradhan RL, Lakhey S, Pandey BK, Manandhar RR, Rijal KP, Sharma S. External and Internal Fixation for Comminuted Intra-articular Fractures of Distal Radius. KUMJ, 7, 4, 367$371,2009$.

6. Diass JJ, Wray CC, Jones JM, Gregg PJ. The value of early mobilization in the treatment of Colles' fractures. J Bone Joint Surg 1987;69: Br 727-729

7. Osada D, Kame Si, Masuzaki K, Takai M, Kameda M, Tamai K. Prospective Study of Distal Radius Fractures Treated With a Volar Locking Plate System. J Hand Surg 2008;33A:691 - 700

8. Melone CP Jr. Open treatment for displaced articular fractures of the distal radius. Clin Orthop. 1986; 202:10311.

9. Missakian ML, Cooney WP, Amadio PC, Glidewell HL. Open reduction and internal fixation for distal radius fractures. J Hand Surg [Am]. 1992;17: 745-55.
10. Rozental T D,. Blazar PE,. Franko OI,. Chacko AT,. Earp BE,. Day CS. J Bone Joint Surg. 2009;91: A. 1837-1846.

11. Ruch DS, Papadonikolakis A. Volar versus dorsal plating in the management of intra-articular distal radius fractures. J Hand Surg Am. 2006;31:9-16.

12. Othman AY. Fixation of dorsally displaced distal radius fractures with volar plate. J Trauma 2009; 66 ;1416-1420

13. Kandemir U, Matityahu A, Desai R, Puttlitz C. Does a volar locking plate provide equivalent stability as a dorsal nonlocking plate in a dorsally comminuted distal radius fracture?: a biomechanical study $\mathrm{J}$ Orthop Trauma 2008;22:605-610

14. Osada D, Viegas SF, Shah MA, Morris RP, Patterson RM. Comparison of different distal radius dorsal and volar fracture fixation plates: a biomechanical study. J Hand Surg. Am 2003;28:94-104

15. Smith DW, Henry MH. Volar fixed-angle plating of the distal radius. J Am Acad Orthop Surg. 2005;13:28 -36.

16. Current Concepts in Volar Fixed-angle Fixation of Unstable Distal Radius Fractures OrbayJL, Touhami A Clin Orthop Relat Res 445, 58-67

17. Drobetz H, Kutscha-Lissberg E. Osteosynthesis of distal radial fractures with a volar locking screw plate system. Int Orthop 2003;27:1-6.

18. Nana AD, Joshi A, Lichtman DM. Plating of the Distal Radius. J Am Acad Orthop Surg. 13, 159-171.

19. Chung KC, Petruska EA. Treatment of unstable distal radius fractures with locking plating system. Surgical technique J. Bone Joint Surg 2007;89 A. Suppl 2:256-66

20. Cooney WP, Bussey R, Dobyns JH, Linscheid RL. Difficult wrist fractures. Perilunate fracture-dislocations of the wrist. Clin Orthop. 1987; 214:136-47.

21. Zenke Y, Sakai A, Oshige T, Moritani S, Nakamura T. The effect of an associated ulnar styloid fracture on the outcome after fixation of a fracture of the distal radius. JBJS 2009; 91; Br 102-107

22. Willis AA, Kutsumi K, Zobitz ME, Cooney WP. Internal fixation of dorsally displaced fractures of the distal part of the radius: A biomechanical analysis of volar plate fracture stability. JBJS Am 200688:11;2411-2417

23. Arora R, Lutz M, Fritz D, Zimmermann R, Oberladstatter J, Gabl M. Palmar locking plate for treatment of unstable dorsal dislocated distal radius fractures. Arch Orthop Trauma Surg 2005; 125:399-404. 
24. Leung F, Zhu L, Ho H, Lu WW, Chow SP. Palmar plate fixation of AO type $\mathrm{C} 2$ fracture of distal radius using a locking compression plate-a biomechanical study in a cadaveric model. J Hand Surg 2003;28B:263-266

25. Hakimi M, Jungbluth P, Windolf J, Wild M. The Journal of Hand Surgery (European Volume, 2010) 35E: 4: 283-288

26. Rotational fluoroscopy assists in detection of intra-articular screw penetration during volar plating of the distal radius. J Hand Surg Am 2010;35:619-627

27. Displaced distal radial fractures treated using volar locking plates: maintenance of normal anatomy. Stevenson I, Carnegie CA, Christie EM, Kumar K, Johnstone A. J Trauma 2009:67; 612-616.
28. Schuind FA, Linscheid RL, An KN, Chao EY. A normal data base of posteroanterior roentgenographic measurements of the wrist. J Bone Joint Surg 1992;74: A. 1418-1429

29. Knight D, Hajducka C, Will E, McQueen M. Locked volar plating for unstable distal radius fractures: clinical and radiological outcomes. Injury,2010:41; 184-189<smiles>C1C2C3C2C2C1C32</smiles>

\section{CORRESPONDENCE:}

Dr. Rabindra Lal Pradhan

Department of Orthopaedic Surgery

Kathmandu Medical Teaching Hospital

Sinamangal, Kathmandu, Nepal

E mail : rabi.ortho@gmail.coms 